\title{
A small 3D-printing model of macroadenomas for endoscopic endonasal surgery
}

\author{
Xing Huang ${ }^{1} \cdot$ Zhen Liu $^{1} \cdot$ Xuan Wang ${ }^{1} \cdot$ Xu-dong $\mathrm{Li}^{1} \cdot$ Kai Cheng $^{1} \cdot$ Yan Zhou ${ }^{1} \cdot$ Xiao-bing Jiang $^{1}$ (D)
}

Published online: 30 November 2018

(c) The Author(s) 2018

\begin{abstract}
Purpose This paper examines the application of 3D printing technology in the endoscopic endonasal approach for the treatment of macroadenomas.

Methods We have retrospectively analysed 20 patients who diagnosed with macroadenoma underwent endoscopic transsphenoidal surgery in Wuhan Union hospital from January 2017 to May 2017. Among the 20 patients, 10 patients received the service of 3D printing technology preoperatively. The data of 3D processing and clinical result were recorded for further evaluation.

Results The 10 patients who received the service had a successful 3D printed model of their tumors, it shows the anatomy of sphenoid sinus, tumor location which were in good agreement with our intraoperative observations. The 10 patients who received the service had a less operation time (127.0 \pm 15.53 vs. $143.40 \pm 17.89)$, blood loss $(159.90 \pm 12.31$ vs. $170.00 \pm 29.06)$ and less postoperative complication rate ( $20 \%$ vs. $40 \%)$. the design time of the $3 \mathrm{D}$ images varies $2 \mathrm{~h} 10 \mathrm{~min}$ to $4 \mathrm{~h} 32 \mathrm{~min}$. the printing time of the 3D models varies $10 \mathrm{~h} 12 \mathrm{~min}$ to $22 \mathrm{~h} 34 \mathrm{~min}$.

Conclusions The use of 3D printing technology has unquestionable potential applications to endoscopic endonasal approach for macroadenomas, in particular reflecting the complicated anatomy of sphenoid sinus and tumor location. Owing to the advantages of 3D printing technology, it may help the patients get a good prognosis.
\end{abstract}

Keywords 3D printing $\cdot$ Endoscopic endonasal approach $\cdot$ Macroadenomas $\cdot$ Anatomical modeling $\cdot$ Surgical simulation

$\begin{array}{ll}\text { Abbreviations } \\ \text { MRI } & \text { Magnetic resonance imaging } \\ \text { MRA } & \text { Magnetic resonance angiography } \\ \text { CT } & \text { Computed tomography } \\ \text { CTA } & \text { CT-angiography } \\ \text { DICOM } & \text { Digital imaging and communications in } \\ & \text { medicine }\end{array}$

\section{Introduction}

The endoscopic endonasal transsphenoidal approach is a common procedure used for skull middle line diseases, such as pituitary adenomas (PAs) and chordoma [1-6]. Its advantages are a rapid recovery, shorter operation time [7],

Xiao-bing Jiang

jxb917@126.com

1 Department of Neurosurgery, Union Hospital, Tongji Medical College, Huazhong University of Science and Technology, Wuhan 430022, Hubei, China less blood loss, better visual results, less trauma to the brain, and fewer seizures [8]. However, this approach is still a challenging procedure for most neurosurgeons [9], especially for beginners. Potential disadvantages of this procedure include the relatively restricted working space and the danger of an inadequate dural repair with cerebrospinal fluid (CSF) leakage and potential for meningitis [10]. Several factors influence the outcome of endoscopic endonasal surgery, including the tumor volume, patient age, lesion location, and sphenoid pneumatolysis [11]. An accurate model of the target tumor structure is a major prerequisite for a successful PAs resection, expecially for macroadenomas, as this may avoid disastrous complications due to suboptimal treatment.

MRI and CT are the benchmark imaging modalities to delineate cerebral PAs in the planning of endoscopic endonasal surgeries. These techniques can provide information such as tumor position and blood supply $[12,13]$. The radiographic evaluation of the skull base anatomy and its relationship to associated tumors is critical for both preoperative planning and intraoperative guidance. Thus, CT and MRI play significant roles in guiding endoscopic 
endonasal procedures. Nevertheless, the target volume from two-dimensional (2D) views does not provide integral information about the tumor structure. Furthermore, one image does not contain the whole information of bone structure and tumor shape. These limitations of MRI and CT have long been acknowledged, especially for PAs with complex shapes.

To overcome the limitations mentioned above, some neurosurgeons prefer the neuronavigation system, which bases on image-guided localization for assistance during the operation, particularly in the localization of tumor and internal carotid arteries [14]. However, this system has some well-known disadvantages, as it is time consuming and expensive, provoking that not all the hospitals can afford it [15]. Furthermore, the surgical planning has to be made based on two-dimensional images, which do not provide sufficient information of the surrounding structures. Therefore, the neuronavigation system still lacks sufficient spatial information to discriminate among the nidus and immediately surrounding normal vessels, such as arteries.

In light of these difficulties and the necessity to precisely define the target to avoid disastrous complications, including bleeding from the internal carotid artery or CSF rhinorrhea, we have attempted to achieve an improved interpretation of each PA's anatomy by printing 3D prototypes of the PAs of individual patients. In this paper, we describe a technique that improves the understanding of complex macroadenomas by $3 \mathrm{D}$ prototyping of individual lesions.

\section{Materials and methods}

\section{Patient selection}

In order to investigate the value of 3D printing technology, patients with macroadenomas who underwent endoscopic endonasal surgery at the Union Hospital of Tongji Medical College, Huazhong University of Science and Technology (Wuhan, China), between January and May 2017 were selected for rereview and treatment planning. All the surgeries were completed by one experienced neurosurgeon. We selected cases in which the identification of the tumor location was not intuitive. Difficulties were due to the structure of different sphenoid sinus bones and tumor components, as, for example, the presence of too much of the sphenoid sinus septa, which made their location difficult, an unclear tumor location, and widespread tumors. Different combinations of these factors were present in different patient cases. After inspection, 20 cases that had matched tumor size, no other diseases and almost the same difficulties mentioned above were enrolled and ten cases who got the service of 3D printing technology were experimental group and ten cases who did not were control group. All patients underwent MRI and CT examinations, and age, gender, symptom, tumor type, images, postoperative complication, operation time and blood loss were recorded for each patient. The protocol for this study was reviewed and approved by the Ethics Committee of Tongji Medical College, Huazhong University of Science and Technology.

\section{Image acquisition and 3D printing}

Imaging data from CT and MRI scans performed for clinical purposes were used for this study. To obtain the data in the stereolithography file format $\left({ }^{*}\right.$.stl) necessary for 3D printing, we used the standard DICOM image files obtained from CT and MRI. The slice thicknesses of the CT scans were $0.625 \mathrm{~mm}$, and the slice thicknesses of the MRI scans were $1 \mathrm{~mm}$. The freely available software MIMICS (Materialise, Leuven, Belgium) was used to convert the CT data into a 3D model. Using the program's automated segmentation feature, the CT scans were selectively segmented using intensity thresholds to isolate the bone and the internal carotid artery. We reviewed the automatic segmentations, and an initial manual segmentation was performed to minimize the artifacts and include any of the following desired bone areas: sphenoid sinus without the anterior wall, planum sphenoid, internal carotid artery, sella turcica, upper clivus, and anterior and posterior clinoid processes. After this segmentation, we obtained the $3 \mathrm{D}$ images of the bone and the internal carotid artery. We performed the same procedure on the MRI data to obtain the 3D image of the tumor. Finally, we formed a virtual model by putting these two parts together according to the patient's anatomy. The final virtual models were converted into .stl files and imported into the 3D printer. This printer used Fused Deposition Modeling Technology, which prints out the material by deposing layer by layer of acrylate resin with the layer thickness $0.245 \mathrm{~mm}$.

\section{Model application}

First, we observed the tumor site in the model and the anatomical situation in the sphenoidal sinus preoperatively. Then, the surgical approach was confirmed, and the central septum of the sphenoidal sinus was removed with the aid of an endoscopy system to expose the sella turcica and confirm the location of the internal carotid artery tumor in the sella turcica. The exposed area of the sellar floor was determined according to the contact status between the tumor and the sellar floor, and the size of the area was measured. On the day of the surgery, the tumor was excised according to the predetermined route, and the crucial anatomical sites were compared with the model. The expose area of the sellar floor was measured after tumor resection was completed. 


\section{Statistical analysis}

All the data are expressed as the mean \pm SD and Mann-Whitney test or $\chi^{2}$ test was used for comparison between groups, as approprite. A p value $<0.05$ was considered statistically significant. All the data analyses were performed with SPSS (version 21).

\section{Results}

\section{Patients' information}

We carried out a retrospective analysis of 20 macroadenoma patients, of which 10 patients had recieved the service of 3D printing technology. In this group, 5 were males and 5 were females, with which average age was $41.20 \pm 11.84$ years. All patients underwent endoscopic transsphenoidal surgery, of which 9 patients underwent complete resection, while 1 patient underwent partial resection. Postoperative pathological examination revealed four cases of non-functioning adenomas, three case of PRL-secreting adenoma, three cases of growth hormone-secreting PAs. After surgery, among the 10 patients, 1 patients experienced electrolyte disorders, 1 patient experienced diabetes insipidus, and no patient experienced CSF rhinorrhea. The average operation time and blood loss were $127.0 \pm 15.53 \mathrm{~min}$ and $143.40 \pm 17.89 \mathrm{ml}$ respectively.

In the group of patients who had not received the service, 5 were males and 5 were females, with which average age was $44.40 \pm 8.45$ years. All 10 patients were macroadenomas. All patients underwent endoscopic transsphenoidal surgery, of which 8 patients underwent complete resection, while 2 patient underwent subtotal resection. Postoperative pathological examination revealed five cases of non-functioning adenomas, three case of PRL-secreting adenoma, two cases of growth hormone-secreting PAs. After surgery, among the 10 patients, 2 patients experienced electrolyte disorders, 1 patient experienced diabetes insipidus, and 1 patient experienced CSF rhinorrhea. The average operation time and blood loss were $159.90 \pm 12.31 \mathrm{~min}$ and $170.00 \pm 29.06 \mathrm{ml}$ respectively(details shown in Table 1).

\section{The 3D processing and clinical application}

The PA models of the 10 patients were successfully printed, showing size, site, and surrounding structure of the tumors (detailed information shown in Tables 2, 3). The design time of the 3D images varies $2 \mathrm{~h} 10 \mathrm{~min}$ to $4 \mathrm{~h} 32 \mathrm{~min}$. The printing time of the 3D models varies $10 \mathrm{~h} 12 \mathrm{~min}$ to $22 \mathrm{~h}$ $34 \mathrm{~min}$. The appearence of model were clear and neat. The results of printing were great satisfaction. During the operation, the outline of sphenoid septation, sellar floor, carotid
Table 1 Summary of patients' data

\begin{tabular}{lll}
\hline & Patients with 3D printing & $\begin{array}{l}\text { Patients } \\
\text { without 3D } \\
\text { printing }\end{array}$ \\
\hline Gender & \\
Male & 5 & 5 \\
Female & 5 & 5 \\
Age (years) & $41.20 \pm 11.84$ & $44.40 \pm 8.45$ \\
Symptom & & \\
Asymptomatic & 5 & 3 \\
Headache & 2 & 4 \\
Acromegaly & 2 & 1 \\
Visual impairment & 1 & 2 \\
Pathological diagnosis & & \\
Non-functioning & 4 & 5 \\
$\quad$ adenoma & & 3 \\
PRL-secreting adenoma & 3 & 2 \\
GH-secreting adenoma & 3 & $8(80 \%)$ \\
The gross total resection & $9(90 \%)$ & $4(40 \%)$ \\
Postoperative complica- & $2(20 \%)$ & $143.40 \pm 17.89$ \\
tion & & $170.00 \pm 29.06$ \\
Operation time (min)* & $127.0 \pm 15.53$ & \\
Blood loss (ml)* & $159.90 \pm 12.31$ & \\
\hline
\end{tabular}

$P R L$ prolactin, $G H$ growth hormone,

$*$ There is difference between them $(\mathrm{p}<0.05)$

protuberance, tumor location was same with the models. The expose area of the model and patient of sella floor were measured as $1.01 \pm 0.23$ and $0.98 \pm 0.31$ which the difference is not statistically significant.

\section{Illustration cases}

\section{Case 1}

A 62-year-old male patient with acromegaly sought treatment at our hospital for intermittent headaches. MRI and CT showed a $1.5 \times 1.0 \times 1.3 \mathrm{~cm}$ space-occupying lesion at the sella turcica (Fig. 1A, B), which was diagnosed as a pituitary macroadenoma. Preoperative endocrine examinations showed elevated growth hormone levels, and the patient was advised to undergo endoscopic transsphenoidal surgery. We employed 3D-printing technology to reconstruct a model of the patient's tumor (Fig. 1C, D). This model has been used as demonstration object to actively communicate the patient's condition with his relatives, which led to good communication results. On the model, we also planned the surgical approach and practiced the surgical manipulation, which provided important guidance for the surgery, leading to full tumor resection. Pathological examination showed that the patient's tumor 
Table 2 Generalization of 3D processing

\begin{tabular}{|c|c|c|c|c|c|}
\hline Case & Images & Design time & Material & Printing time & Satisfaction \\
\hline 1 & CTA, MRI & $2 \mathrm{~h} 43 \mathrm{~min}$ & Acrylate resin & 11 h 36 min & Yes \\
\hline 2 & CTA, MRI & $2 \mathrm{~h} 35 \mathrm{~min}$ & Acrylate resin & $10 \mathrm{~h} 12 \mathrm{~min}$ & Yes \\
\hline 3 & CTA, MRI & $4 \mathrm{~h} 32 \mathrm{~min}$ & Acrylate resin & 22 h 34 min & Yes \\
\hline 4 & CTA, MRI & $2 \mathrm{~h} 40 \mathrm{~min}$ & Acrylate resin & $11 \mathrm{~h} 15 \mathrm{~min}$ & Yes \\
\hline 5 & CTA, MRI & $2 \mathrm{~h} 10 \mathrm{~min}$ & Acrylate resin & $10 \mathrm{~h} 20 \mathrm{~min}$ & Yes \\
\hline 6 & CTA, MRI & $2 \mathrm{~h} 50 \mathrm{~min}$ & Acrylate resin & $10 \mathrm{~h} 24 \mathrm{~min}$ & Yes \\
\hline 7 & CTA, MRI & $2 \mathrm{~h} 56 \mathrm{~min}$ & Acrylate resin & $13 \mathrm{~h} 37 \mathrm{~min}$ & Yes \\
\hline 8 & CTA, MRI & $3 \mathrm{~h} 15 \mathrm{~min}$ & Acrylate resin & $16 \mathrm{~h} 23 \mathrm{~min}$ & Yes \\
\hline 9 & CT, MRA, MRI & $3 \mathrm{~h} 55 \mathrm{~min}$ & Acrylate resin & $12 \mathrm{~h} 21 \mathrm{~min}$ & Yes \\
\hline 10 & CTA, MRI & $3 \mathrm{~h} 10 \mathrm{~min}$ & Acrylate resin & 12 h 54 min & Yes \\
\hline
\end{tabular}

Table 3 Application of the 3D-printing model

\begin{tabular}{lll}
\hline & Printing model & Intraoperative observation \\
\hline Sphenoid septation & Clear & Identical to the model \\
Sellar floor & Clear & Identical to the model \\
Carotid protuberance & Clear & Identical to the model \\
Tumor location & Clear & Identical to the model \\
Exposed area $\left(\mathrm{cm}^{2}\right)^{\mathrm{a}}$ & $1.01 \pm 0.23$ & $0.98 \pm 0.31$ \\
\hline
\end{tabular}

${ }^{\mathrm{a}}$ There is no difference between them $(\mathrm{p}>0.05)$

was a growth hormone-secreting PA. No complications occurred after the surgery, and the patient was successfully discharged.

\section{Case 2}

A 28-year-old female patient with acromegaly sought treatment at our hospital for poor glucose control. MRI and $\mathrm{CT}$ showed a $3.9 \times 2.4 \times 3.3 \mathrm{~cm}$ space-occupying lesion in the sella turcica region (Fig. 2A, B). The patient was diagnosed with pituitary macroadenoma, and preoperative endocrine examinations showed elevated growth hormone levels. We employed 3D-printing technology to reconstruct a model of the patient's tumor (Fig. 2C, D) and used the model as a demonstration object to actively communicate the patient's condition with his relatives. We recommended to the patient to undergo first a transsphenoidal surgery to remove the intrasellar tumor and then a craniotomy to remove the suprasellar tumor. We obtained good condition communication results. At the same time, we planned the surgical approach on the model and practiced the surgical manipulation, which provided important guidance for the surgery. Pathological examination showed that the patient's tumor was a growth hormone-secreting PA. No complications occurred after the surgery, and the patient was successfully discharged. Three months later, the patient went for craniotomy at our hospital, and the tumor was fully resected.

\section{Discussion}

3D-printing technology is an emerging technology with wide potential applications in various occupations and industries. As it is highly precise and allows personalization, 3D-printing technology has started to be applied in medicine in recent years $[16,17]$. In neurosurgery, 3D-printing technology can provide models for the patients' disease characteristics, such as skull defects [18], brain tumors [19], intracranial aneurysms [20], and intracranial vascular malformations [21]. 3D-printing technology provides tools that aid in the resection of tumors, such as positioning models for the resection of tumors in brain functional regions [22] and navigation models for spinal surgery [23, 24]. 3D-printing technology provides us with opportunities for surgery practice on the model, such as simulation of cerebral aneurysm clipping surgery [25] and modelling of intraventricular tumor resection [26]. Benign pituitary tumors are located in the midline skull base region and present one of the most commonly seen tumors in the brain. These tumors are deep and anatomically complex. Currently, the main surgical treatment used for tumor resection is transsphenoidal surgery. Although the surgical approach is carried out via natural channels (bilateral nasal cavity), decreases injury to the patient, and is characterized by less damage, less complications, and faster recovery, clinicians are usually confused by the complex anatomical structures, which limit the promotion of this technique. In fact, in some cases, a digital $3 \mathrm{D}$ reconstruction of the key anatomy is sufficient for the experienced surgeon to study or it is not necessary to have a tangible 3D printed model, but in some complicated cases, 3D printed model provided us a valuable tools for surgical or anatomic considerations. In this artical, we combined endoscopic surgery with 3D-printing 
technology and obtained good clinical outcomes, which are reported in the following.

\section{Model selection}

Previously, many papers about the use of 3D printing in medicine mentioned that 3D-printed models are time and money consuming $[27,28]$, which impedes the application and promotion of $3 \mathrm{D}$ printing in medicine. In order to solve this problem, we limited the printed model to reflect the surrounding anatomical structures of the tumor. This facilitates image reconstruction in the computer and can reduce the loss of local details. In addition, it facilitates rapid printing, reduces material wastage, and reduces economic costs. In transsphenoidal surgery, the key to the success of the entire surgical process is the local anatomical status in the sphenoidal sinus and the relationship of the tumor with surrounding blood vessels and nerves. Our printed model nicely visualized these structures, which fulfilled our requirements. The color of the entire printed model was white. In order to better visualize the tumor, blood vessels, and bones, we used different labeling colors to facilitate the communication with the patients' relatives on the patients' conditions. The model printing time ranged from $10 \mathrm{~h} 12 \mathrm{~min}$ to $22 \mathrm{~h} 34 \mathrm{~min}$, which was completely within the time frame that we can control. Therefore, choosing the local area of the model for printing has some advantages.

\section{Surgical planning and clinical results}

The models we printed reflected the situation of the sphenoidal sinus bone, the tumor, and the blood vessels in the sella turcica region. This realistically exhibited the anatomical relationships at the surgical site and provided us with a foundation for obtaining good surgery outcomes. Through the model, we understood the orientation of the intraseptal bone in the sphenoidal sinus, the morphology of the sellar floor, and the route of the internal carotid artery in the sellar floor, and roughly determined the site of the tumor before surgery. Subsequently, we performed simulated endoscopic manipulations on the model to remove the septal bone in the sphenoidal sinus, fully expose the sellar floor, and show the tumor site. In addition, we also measured the size of the removed sellar floor area to improve the precision of our surgery. In case 1 , it was difficult to outline the 3D image of the tumor from 2D images. Therefore, 3D-printing technology was used to realistically restore the relationships of the spatial location of the tumor. Before surgery, we planned the exposure of the sellar floor to reduce damage to adjacent important structures (Fig. 3), which reliably assured good surgical outcomes. In case 2, the tumor exhibited an extremely irregular morphology, and the suprasellar tumor growth

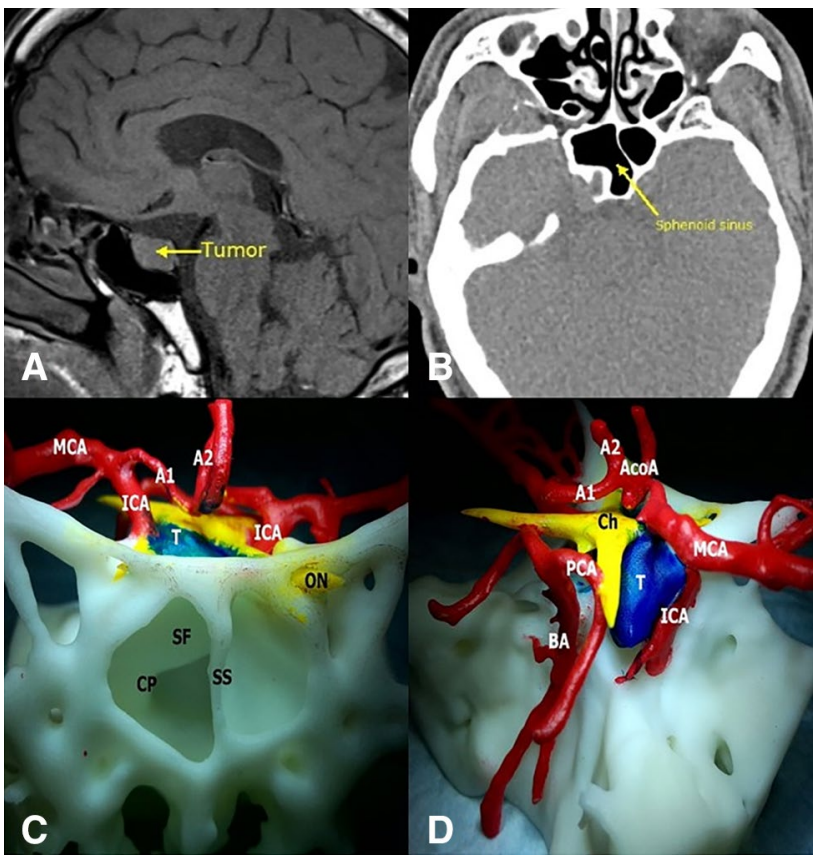

Fig. 1 a MRI of the sella turcica region showing tumor lesions. The yellow arrow points to the tumor. b CT of the sphenoidal sinus. The yellow arrow points to the sphenoidal sinus. c, d Frontal and lateral views. $S F$ sellar floor, $S S$ sphenoid septation, $C P$ carotid protuberance, $A 1$ A1 segment of the anterior cerebral artery, $B A$ basilar artery, $P C A$ posterior cerebral artery, $A 2$ A2 segment of the anterior cerebral artery, $C h$ chiasm, $T$ tumor, $O N$ optic nerve, AcoA anterior communicating artery, $M C A$ middle cerebral artery

region was relatively extensive, as it invaded the anterior skull base and wrapped around the left side of the anterior communicating artery (Fig. 4). Therefore, dissecting the tumor was relatively complex. After careful consideration, we decided to adopt a two-stage surgery. Firstly, endoscopic transsphenoidal surgery was used to remove the intrasellar tumor, while the sella turcica septum was not resected to prevent CSF rhinorrhea. After the patient had recovered well from the surgery, a craniotomy was conducted to excise the suprasellar tumor. Results proved that our strategy was successfull. This shows that 3D-printed models are not only useful for pre-surgery practice, but can also visualize the tumor in the sella turcica region. Therefore, 3D-printed technology provides valuable assistance in making surgery decisions.

In order to further study the clinical value of 3D printing, we analyzed the data of patients with the same size of the pituitary adenoma, and made statistical analysis from the time of operation and the amount of blood loss during the operation. From the Table 1, we can see that the patients with the help of 3D printing technology had a less operation time $(p=0.007)$ and blood loss $(p=0.009)$. As a result, the experimental group had a less postoperative complications rate ( $20 \%$ vs. $40 \%$ ). Although the datas 


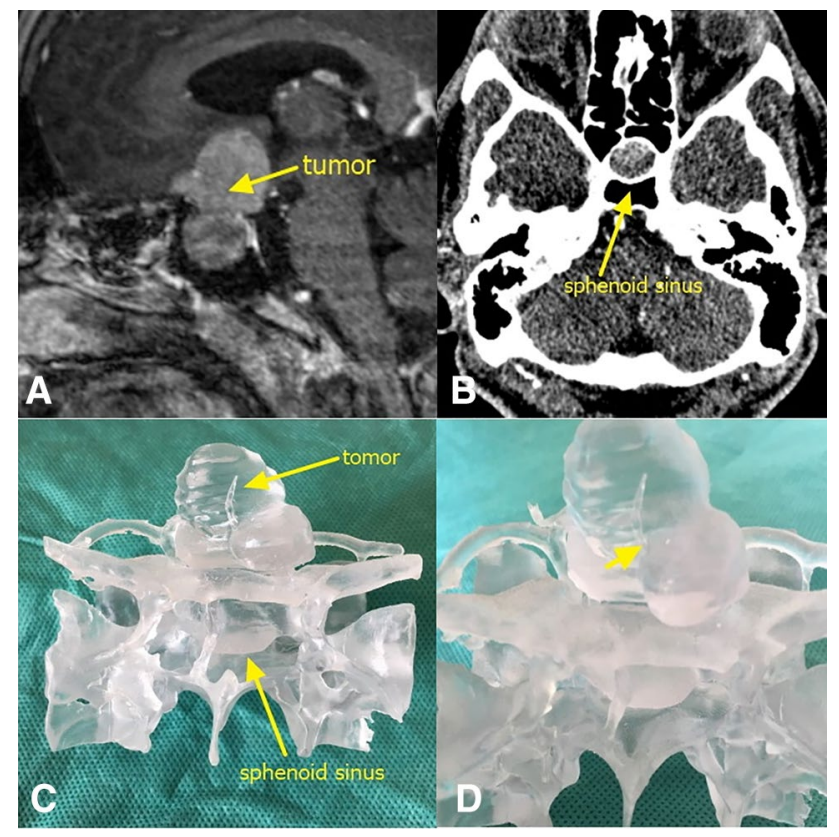

Fig. 2 a MRI of the sella turcica region showing tumor lesions. The yellow arrow points to the tumor. b CT of the sphenoidal sinus. The yellow arrow points to the sphenoidal sinus. c Frontal view of the 3D-printed tumor model. d Enlarged image of a part of the tumor. The yellow arrow shows that the tumor wraps around the left side of the anterior communicating artery

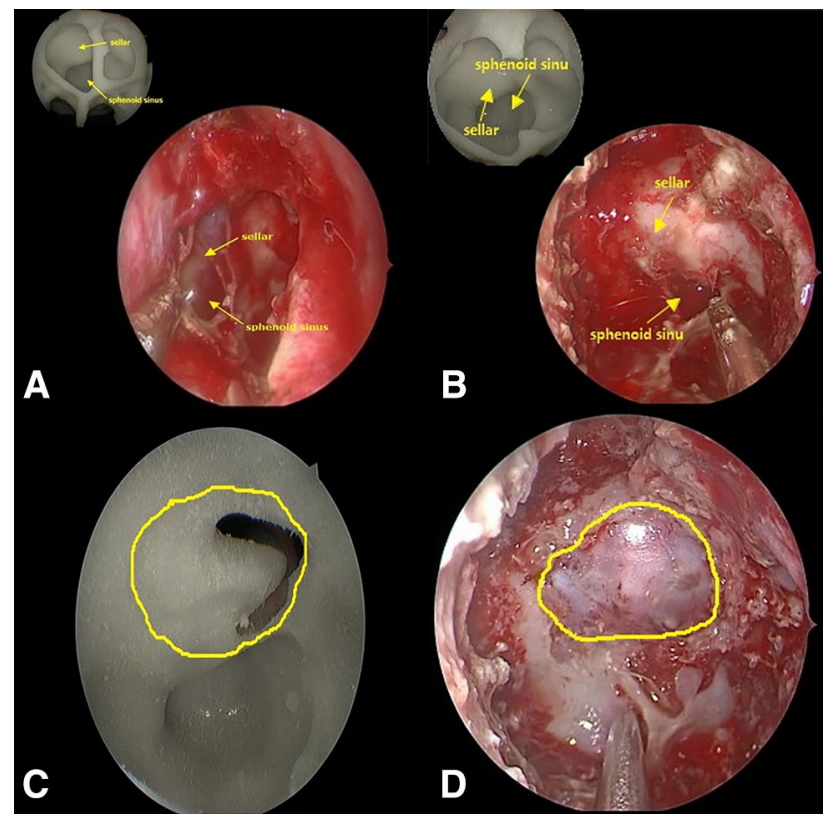

Fig. 3 a Endoscopy of the anatomical status of the sphenoidal sinus and copmparing with the model. b Exposed sellar floor after removal of the septal bone and copmparing with the model. $\mathbf{c}$ Tumor site after removal of the sellar floor bone. d Exposed area of the sellar floor observed in surgery need more support, but the 3D model really make surgeon become more confidence and aware of the vital anatomy structures.

\section{Patient communication and education}

It is widely known that neurosurgeon is a challenging career with high risks and intensity. Surgery risks are higher due to the importance of the lesion site and the complexity of the intracranial structures. However, during communication of the patient's condition with relatives with limited medical knowledge it is difficult to reach a consensus, as physicians often use professional terminology to accurately explain the patient's condition. To improve the relatives' understanding of the patient's condition, objects are used to support the professional description of the medical contents. However, this often results in relatives not fully comprehending the patient's condition. On the other hand, by demonstrating color-labeled models to the relatives and informing them about the surgery process and possible postoperative complications, the relatives fully understood our surgical approach and intention and took careful decisions. This shows that our models can produce good condition communication results. For a neurosurgery student or doctor with little clinical practice experience and shallow understanding of anatomical structures at crucial sites, an improvement of their surgical techniques is frequently limited to learning from precepts and examples from senior physicians during surgery. They also often have a shallow understanding of the choice of surgery options for different methods. By showing the 3D-printed models of different tumor patients to such amateurs, a more accurate and deeper impression of key anatomical locations and surrounding blood vessels and nerves can be achieved, which will improve their medical skills as well as their understanding for making better decisions about surgery methods.

\section{Skull base construction}

CSF rhinorrhea has always been one of the major complications in transsphenoidal surgery. It can be caused by inappropriate surgical manipulations and excessively large skull base defects. In order to prevent the occurrence of this complication, we delineated the exposed area of the sellar floor when the sellar floor was fully exposed. This method has two advantages: firstly, it not only reduces damage to surrounding tissue but also avoids CSF rhinorrhea due to excessively large skull defects; secondly, it provides us with supporting data. Once CSF rhinorrhea occurs, we can select materials with a suitable area for repair according to the size of the exposed area. 
Fig. 4 a Endoscopy of the tumor model. b Close-up of the anatomical status of the sphenoidal sinus under endoscopy. c Anatomical status of the sphenoidal sinus observed in surgery. d, e The tumor under the sellae diaphragma was exposed and had been totally removed. f, $\mathbf{g}$ The tumor above the sellae diaphragma had been partially removed by craniotomy (yellow arrow referred to the tumor)



\section{Conclusions}

This study presents the detailed report of the application of 3D-printing technology in transsphenoidal surgery for macroadenomas. All patients had good postoperative recoveries, which proves that the application of 3D-printing technology in transsphenoidal surgery has good prospects. The 3D-printed models allowed understanding the anatomical structures of pituitary tumors at the sella turcica region before the surgery, which was particularly advantageous in the pathology of more complex anatomical structures. Furthermore, this model provided realistic disease characteristics for surgery planning and preoperative practice as well as a foundation to obtain good surgery outcomes. We believe that with its continuous development, 3D-printing technology will be applied in clinical practice in the near future.

Acknowledgements The author would like to thank Professor Xiaobing Jiang for the encouragement to complete this academic work.

\section{Compliance with ethical standards}

Conflict of interest The authors report no conflict of interest concerning the materials or methods used in this study or the findings specified in this paper.

Open Access This article is distributed under the terms of the Creative Commons Attribution 4.0 International License (http://creativeco mmons.org/licenses/by/4.0/), which permits unrestricted use, distribution, and reproduction in any medium, provided you give appropriate credit to the original author(s) and the source, provide a link to the Creative Commons license, and indicate if changes were made.

\section{References}

1. Gondim JA, Schops M, de Almeida JP, de Albuquerque LA, Gomes E, Ferraz T, Barroso FA (2010) Endoscopic endonasal transsphenoidal surgery: surgical results of 228 pituitary adenomas treated in a pituitary center. Pituitary 13(1):68-77. https:// doi.org/10.1007/s11102-009-0195-X

2. Gui S, Zong X, Wang X, Li C, Zhao P, Cao L, Zhang Y (2016) Classification and surgical approaches for transnasal endoscopic skull base chordoma resection: a 6-year experience with 161 cases. Neurosurg Rev 39(2):321-323. https://doi.org/10.1007/ s10143-015-0696-1

3. Solari D, Cavallo LM, Somma T, Chiaramonte C, Esposito F, Del Basso De Caro M, Cappabianca P (2015) Endoscopic endonasal approach in the management of rathke's cleft cysts. PLoS ONE 10(10):e0139609. https://doi.org/10.1371/journal.pone.0139609

4. Lee JYK, Bohman L-E, Bergsneider M (2014) Contemporary neurosurgical techniques for pituitary tumor resection. J Neurooncol 117(3):437-444. https://doi.org/10.1007/s11060-013-1315-z

5. Catapano D, Sloffer CA, Frank G, Pasquini E, D'Angelo VA, Lanzino G (2006) Comparison between the microscope and endoscope in the direct endonasal extended transsphenoidal approach: anatomical study. J Neurosurg 104(3):419-425. https ://doi.org/10.3171/jns.2006.104.3.419

6. de Divitiis E, Laws ER, Giani U, Iuliano SL, de Divitiis O, Apuzzo MLJ (2015) The current status of endoscopy in transsphenoidal 
surgery: an international survey. World Neurosurg 83(4):447-454. https://doi.org/10.1016/j.wneu.2014.12.029

7. Thomas JG, Gadgil N, Samson SL, Takashima M, Yoshor D (2014) Prospective trial of a short hospital stay protocol after endoscopic endonasal pituitary adenoma surgery. World Neurosurg 81(3-4):576-583. https://doi.org/10.1016/j. wneu.2013.11.014

8. Bander ED, Singh H, Ogilvie CB, Cusic RC, Pisapia DJ, Tsiouris AJ, Anand VK, Schwartz TH (2018) Endoscopic endonasal versus transcranial approach to tuberculum sellae and planum sphenoidale meningiomas in a similar cohort of patients. J Neurosurg 128(1):40-48. https://doi.org/10.3171/2016.9.JNS16823

9. Kasemsiri P, Carrau RL, Ditzel Filho LF, Prevedello DM, Otto BA, Old M, de Lara D, Kassam AB (2014) Advantages and limitations of endoscopic endonasal approaches to the skull base. World Neurosurg 82(6 Suppl):S12-S21. https://doi.org/10.1016/j. wneu.2014.07.022

10. Cavallo LM, Messina A, Cappabianca P, Esposito F, de Divitiis E, Gardner P, Tschabitscher M (2005) Endoscopic endonasal surgery of the midline skull base: anatomical study and clinical considerations. Neurosurg Focus 19(1):E2

11. Juraschka K, Khan OH, Godoy BL, Monsalves E, Kilian A, Krischek B, Ghare A, Vescan A, Gentili F, Zadeh G (2014) Endoscopic endonasal transsphenoidal approach to large and giant pituitary adenomas: institutional experience and predictors of extent of resection. J Neurosurg 121(1):75-83. https://doi. org/10.3171/2014.3.JNS131679

12. Nunes RH, Abello AL, Zanation AM, Sasaki-Adams D, Huang BY (2016) Imaging in endoscopic cranial skull base and pituitary surgery. Otolaryngol Clin North Am 49(1):33-62. https:// doi.org/10.1016/j.otc.2015.09.003

13. Gardner PA, Kassam AB, Rothfus WE, Snyderman CH, Carrau RL (2008) Preoperative and intraoperative imaging for endoscopic endonasal approaches to the skull base. Otolaryngol Clin North Am 41(1):215-230. https://doi.org/10.1016/j.otc.2007.10.010 vii.

14. Linsler S, Antes S, Senger S, Oertel J (2016) The use of intraoperative computed tomography navigation in pituitary surgery promises a better intraoperative orientation in special cases. $\mathbf{J}$ Neurosci Rural Pract 7(4):598-602. https://doi.org/10.4103/09763147.186977

15. Moses ZB, Mayer RR, Strickland BA, Kretzer RM, Wolinsky JP, Gokaslan ZL, Baaj AA (2013) Neuronavigation in minimally invasive spine surgery. Neurosurg Focus 35(2):E12. https://doi. org/10.3171/2013.5.FOCUS13150

16. Malik HH, Darwood AR, Shaunak S, Kulatilake P, El-Hilly AA, Mulki O, Baskaradas A (2015) Three-dimensional printing in surgery: a review of current surgical applications. J Surg Res 199(2):512-522. https://doi.org/10.1016/j.jss.2015.06.051

17. Zadpoor AA, Malda J (2017) Additive manufacturing of biomaterials, tissues, and organs. Ann Biomed Eng 45(1):1-11. https:// doi.org/10.1007/s10439-016-1719-y

18. Park EK, Lim JY, Yun IS, Kim JS, Woo SH, Kim DS, Shim KW (2016) Cranioplasty enhanced by three-dimensional printing: custom-made three-dimensional-printed titanium implants for skull defects. J Craniofac Surg 27(4):943-949. https://doi. org/10.1097/SCS.0000000000002656

19. Muelleman TJ, Peterson J, Chowdhury NI, Gorup J, Camarata P, Lin J (2016) Individualized surgical approach planning for petroclival tumors using a 3D printer. J Neurol Surg B 77(3):243-248. https://doi.org/10.1055/s-0035-1566253

20. Anderson JR, Thompson WL, Alkattan AK, Diaz O, Klucznik R, Zhang YJ, Britz GW, Grossman RG, Karmonik C (2016) Threedimensional printing of anatomically accurate, patient specific intracranial aneurysm models. J Neurointerv Surg 8(5):517-520. https://doi.org/10.1136/neurintsurg-2015-011686

21. Conti A, Pontoriero A, Iati G, Marino D, La Torre D, Vinci S, Germano A, Pergolizzi S, Tomasello F (2016) 3D-printing of arteriovenous malformations for radiosurgical treatment: pushing anatomy understanding to real boundaries. Cureus 8(4):e594. https://doi.org/10.7759/cureus.594

22. Spottiswoode BS, van den Heever DJ, Chang Y, Engelhardt S, Du Plessis S, Nicolls F, Hartzenberg HB, Gretschel A (2013) Preoperative three-dimensional model creation of magnetic resonance brain images as a tool to assist neurosurgical planning. Stereotact Funct Neurosurg 91(3):162-169. https://doi.org/10.1159/00034 5264

23. Kawaguchi Y, Nakano M, Yasuda T, Seki S, Hori T, Kimura T (2012) Development of a new technique for pedicle screw and Magerl screw insertion using a 3-dimensional image guide. Spine 37(23):1983-1988. https://doi.org/10.1097/BRS.0b013e3182 $5 \mathrm{ab} 547$

24. Lu S, Xu YQ, Zhang YZ, Xie L, Guo H, Li DP (2009) A novel computer-assisted drill guide template for placement of C2 laminar screws. Eur Spine J 18(9):1379-1385. https://doi.org/10.1007/ s00586-009-1051-4

25. Ryan JR, Almefty KK, Nakaji P, Frakes DH (2016) Cerebral aneurysm clipping surgery simulation using patient-specific 3D printing and silicone casting. World Neurosurg 88:175-181. https ://doi.org/10.1016/j.wneu.2015.12.102

26. Waran V, Narayanan V, Karuppiah R, Thambynayagam HC, Muthusamy KA, Rahman ZA, Kirollos RW (2015) Neurosurgical endoscopic training via a realistic 3-dimensional model with pathology. Simul Healthc 10(1):43-48. https://doi.org/10.1097/ SIH.0000000000000060

27. Ploch CC, Mansi C, Jayamohan J, Kuhl E (2016) Using 3D printing to create personalized brain models for neurosurgical training and preoperative planning. World Neurosurg 90:668-674. https:// doi.org/10.1016/j.wneu.2016.02.081

28. Morales-Gomez JA, Garcia-Estrada E, Leos-Bortoni JE, DelgadoBrito M, Flores-Huerta LE, De La Cruz-Arriaga AA, Torres-Diaz LJ, de Leon ARM (2018) Cranioplasty with a low-cost customized polymethylmethacrylate implant using a desktop $3 \mathrm{D}$ printer. J Neurosurg. https://doi.org/10.3171/2017.12 